\title{
Automation of Checking Math Tasks on the Analytical Geometry Nomotex E-course
}

\author{
Yury I. Dimitrienko ${ }^{1}$, Kirill M. Zubarev ${ }^{1 *}$, Elena A. Gubareva ${ }^{1}$, Tatyana L. Ivanova ${ }^{1}$, and \\ Alexander $V$. Alesin ${ }^{1}$ \\ ${ }^{1}$ Bauman Moscow State Technical University, 2nd Baumanskaya str., 5/1, 105005, Moscow, Russia
}

\begin{abstract}
In this article, the authors consider the problem of automatic check of tasks on the example of tasks on the topic of lines and planes. The authors raise the question of the influence of arithmetic errors on automatic verification. The paper discusses methods that will reduce the impact of arithmetic error on automated problem checking. The article provides several examples that are given to students to solve at control events held at the Bauman Moscow State Technical University.
\end{abstract}

\section{Introduction}

The International and domestic experience in training engineering personnel shows that in recent decades there has been a change in the paradigm of engineering activities, there is a transition from the established centuries-old technology of engineering activity, as a heuristic work based on the generalization of previous experience, to a new technology based on computer modelling and design [1]. To ensure the transition to a new engineering paradigm, the technology of teaching mathematics for future engineers must be fundamentally changed [2].

Teaching mathematics can no longer be based on approaches and technologies that do not use modern advances in computer and information technology [3, 4]. Only by applying the symbiosis of the traditional approach in teaching mathematics and new mathematical educational technologies that use the cognitive-visual approach, structuring mathematical knowledge and specialized software tools that allow visualizing the concepts of analytical mathematics and provide a practical basis for these concepts, it is possible to achieve the necessary level of training of engineering personnel for knowledge-intensive sectors of the country's economy $[5,6,7]$.

In this regard, the Digital Learning System Nomotex was developed, which is a tool for classroom and distance learning [7, 8]. The functionality of the DLS Nomotex allows you to conduct lectures, seminars, take homework assignments, and also carry out control activities. Control activities consist of tests where you need to choose the correct answer and tasks with the answer [9, 10]. Checking tasks in DLS Nomotex is carried out automatically using the Phyton $[11,12]$.

* Corresponding author: zubarevkm@bmstu.ru 


\section{Automatic check of tasks in DLS Nomotex}

\subsection{Control works in DLS Nometex}

One of the possibilities of DLS Nomotex is to carry out control measures. In order to save the teacher's time, the assessment of problems is carried out automatically. Control activities are carried out in computer classes and represent the following sequence of actions $[11,12,13]$.

a) The teacher enters the DLS Nomotex, goes to the tab of the personal account.

b) Distributes tickets for the control event. A ticket is a set of tasks containing theoretical testing, which is a question with a choice of one or more correct answers from the proposed ones. As well as practical tasks, which are a task with an answer.

c) A student solves each of the tasks in a random sequence; he is given only one attempt to answer each task.

d) After the completion of the control event, the teacher in his personal account can view the results of the control event, find out the points awarded to students, and also see what tasks a particular student has solved, in which he made mistakes, and which he did not cope with.

Automatic check of assignments significantly saves the teacher's time, but the effect of the arithmetic error made by the student is enhanced. For example, a student solves a problem that is estimated at 5 points, and makes an arithmetic error, and as a result receives an incorrect answer, an automatic check will evaluate such a problem at 0 points. While the teacher would have estimated not only the final answer, but also the progress of the solution and would have estimated the problem at 3-4 points $[14,15]$.

To minimize the impact of such errors in the DLS Nomotex various methods are used, such as, for example, checking the problem by "blocks", for each block the student receives a certain amount of points, so the arithmetic error made at the last stage of solving the problem will not be be critical to the final score.

Another problem of tasks on the topic of lines and planes is the ambiguity of the answer. The equation of a plane and a straight line is not specified uniquely, but depends on the selected normal vector in the case of a plane

This article discusses methods to reduce the impact of such errors on the example of tasks on the topic of lines and planes $[17,18,19]$.

\subsection{Features of tasks on the topic straight lines and planes}

Straight lines and planes is a section of analytical geometry that studies straight lines in a plane and straight lines in space, as well as planes, and the relative position of lines and planes. There are two main types of tasks on this topic. the first type of problems is the problem of constructing a plane that meets the given conditions. The second type is the problem of constructing a straight line that meets specified conditions $[12,13]$.

On control tests in DLS Nomotex they represent a task with an answer. Figure 1 shows an example of a task to build a plane [14]. 




Fig. 1. The problem of finding the equation of the plane.

As can be seen from the figure, the answer to the problem is introduced in the form of coefficients of the general equation of the plane.

$$
A x+B y+C z+D=0
$$

As is known, the equation of the plane is not specified uniquely. The equations $x+y+z+1=0$ and $5 x+5 y+5 z+5=0$ define the same plane, that is, the equation of the plane can be multiplied by any number. Thus, the problem has no single correct answer. To solve this problem, the student's answers are compared with the answers in the DLS Nomotex. Let $\left(A_{1} ; B_{1} ; C_{1} ; D_{1}\right)$ be an array of answers entered by students, and $\left(A_{2} ; B_{2} ; C_{2} ; D_{2}\right)$ an array of answers in the DLS Nomotex, that is, the correct answer, it is necessary to establish whether the answer entered by the student is correct. To do this, compare it with the correct answer, make the proportions for the corresponding elements of the two arrays, then if

$$
\begin{gathered}
\frac{A_{1}}{A_{2}}=\frac{B_{1}}{B_{2}}=\frac{C_{1}}{C_{2}}=\frac{D_{1}}{D_{2}} \\
A^{2}+B^{2}+C^{2} \neq 0
\end{gathered}
$$

then the equations $A_{1} x+B_{1} y+C_{1} z+D_{1}=0$ and $A_{2} x+B_{2} y+C_{2} z+D_{2}=0$ set the same plane, in this case the student's answer is correct. The condition that the sum of the squares of the coefficients is not equal to zero excludes the case when the student enters all the zero coefficients, since the first condition will be fulfilled.

In most cases, the task of constructing a plane can be divided into two stages: finding the normal vector and finding a point belonging to the plane. In the array of answers $\left(A_{1} ; B_{1} ; C_{1} ; D_{1}\right)$, the first three coefficients are responsible for the normal vector $\bar{n}\left(A_{1} ; B_{1} ; C_{1}\right)$, and the last one depends on a point belonging to the plane. In this regard, it was proposed to divide the number of points awarded for the problem as follows: if condition (2) and (3) is satisfied for the first three coefficients introduced by the student $\left(A_{1} ; B_{1} ; C_{1}\right)$, the student is awarded 70 percent of the maximum points, if the latter coefficient also satisfies condition (2), then the student is added another 30 percent of the points. If only the coefficient satisfies conditions (2) and (3), then the students are not awarded points, since it is impossible to find the fourth coefficient without knowing the first three [20, 21].

In problems of finding a straight line, there is also no single answer. Figure 2 shows an example of a task for building a straight line. 




Fig. 2. The problem of finding the equation of a straight line.

The figure shows that the answer to the problem is introduced in the form of the coefficients of the canonical equations of the straight line:

$$
\frac{x-x_{0}}{m}=\frac{y-y_{0}}{n}=\frac{z-z_{0}}{p}
$$

Here $M_{0}\left(x_{0} ; y_{0} ; z_{0}\right)$ is any point belonging to the straight line, and $\dot{q}(m ; n ; p)$ is the direction vector of the straight line. Both the point and the direction vector are not determined uniquely, therefore, there is no single correct answer in the problem. To solve this problem, the student's answers are compared with the answers in the DLS Nomotex. Let $\left(m_{1} ; n_{1} ; p_{1}\right)$ is the direction vector introduced by the student, and $\left(m_{2} ; n_{2} ; p_{2}\right)$ is one of the correct direction vectors in the DLS Nomotex, in order for these vectors to be the direction vector of the same straight line, they must be collinear, that

$$
\frac{m_{1}}{m_{2}}=\frac{n_{1}}{n_{2}}=\frac{p_{1}}{p_{2}}
$$

Let now $\left(x_{1} ; y_{1} ; z_{1}\right)$ be a point entered by a student, and $\left(x_{2} ; y_{2} ; z_{2}\right)$ one of the correct points belonging to the sought line, then the equality

$$
\frac{x_{2}-x_{1}}{m_{2}}=\frac{y_{2}-y_{1}}{n_{2}}=\frac{z_{2}-z_{1}}{p_{2}}
$$

But one of the coordinates of the direction vector can be equal to zero, then in expression (5) we will receive division by 0 , so we will rewrite expression (5) as:

$$
\begin{aligned}
& \left(x_{2}-x_{1}\right) m_{2}=\left(y_{2}-y_{1}\right) l_{2} \\
& \left(x_{2}-x_{1}\right) n_{2}=\left(z_{2}-z_{1}\right) l_{2} \\
& \left(z_{2}-z_{1}\right) m_{2}=\left(y_{2}-y_{1}\right) n_{2}
\end{aligned}
$$

If conditions (4) and (6) are satisfied, then the student has correctly found the equation of the straight line $[12,13]$.

The problem of building a straight line can often be divided into two stages: finding a direction vector and a point lying on this straight line. The fulfillment of condition (4) guarantees that the direction vector introduced by the student is found correctly, and the fulfillment of condition (6) guarantees that the point entered by the student belongs to the sought line, even taking into account that the direction vector is determined incorrectly, because in condition (6) it is used knowingly correct vector $\left(m_{2} ; n_{2} ; p_{2}\right)$. Thus, you can divide the number of points, depending on the condition of the problem, assign a certain number of points for fulfilling condition (4) and for fulfilling condition (6) separately. For example, for the problem in Figure 3. It can be said that determining a point belonging to a 
straight line is more difficult than finding a direction vector. For this task, the following evaluation criteria were established: 70 percent of points for fulfilling condition (6) and 30 percent of points for fulfilling condition (4) $[15,16]$.

\section{Conclusions}

In this paper, the characteristic features of problems on the topic of lines and planes were considered. Various ways of solving the problems arising during the automatic check of tasks on this topic were proposed. The authors described a method that allows you to divide the number of points awarded to a student when solving problems on the construction of lines and planes. It is worth noting that when carrying out control measures at the Bauman Moscow State Technical University, it has been proven that such techniques lead to a decrease in the effect of arithmetic errors on the number of points received for the problem.

\section{References}

1. Ya.I. Kuzminov, M. Carnoy, Panel discussion, Online Learning: How It Affects the University Structure and Economics, Voprosy obrazovaniya, No. 3, pp. 8-43 (2015)

2. V. Gromyko, V. Kazaryan, N. Vasilyev, A. Simakin, S. Anosov, Artificial intelligence as tutoring partner for human intellect, Advances in intelligent systems and computing, № 658, pp. 238-247 (2018)

3. V. Mayorova, O. Zhdanovich, Innovative collaborative educational programs for space systems engineers, Proceedings of the International Astronautical Congress, IAC (2016)

4. G. Procurat, A. Strukova, A. Vukolov, O. Egorova, Generated graphics and game development software in engineering education: Perspectives and experience of usage, Mechanisms and Machine Science, № 64, pp. 123-130 (2019)

5. N. Serdyukova, V. Serdyukov, S. Neustroev, Testing as a feedback in a smart university and as a component of the identification of smart systems, Smart Innovation, Systems and Technologies, № 144, pp. 527-538 (2019)

6. V. Guznenkov, P. Zhurbenko, The Academic Discipline 'Computer Graphics' for the Open Education System, 2018 4th International Conference on Information Technologies in Engineering Education, Inforino 2018 - Proceedings 8581738 (2018)

7. A. Karpov, Education for knowledge society: Learning and scientific innovation environment, Journal of Social Studies Education Research, № 8(3), pp. 201-214 (2017)

8. K.F. Deborah, Practices for Student Success: From Face-to-Face to At-Scale and Back, No. 4, pp. 116-138 (2018)

9. V. Potkonjak, M. Gardner, V. Callaghan, P. Mattila, Ch. Guetl, V. Petrović, K. Jovanovic, Virtual Laboratories for Education in Science, Technology, and Engineering: a Review, Computers \& Education, Vol. 95, pp. 309-327 (2016)

10. B. Gan, T. Menkhoff, R. Smith Smith, Enhancing students' learning process through interactive digital media: New opportunities for collaborative learning, Computers in Human Behavior, Vol. 51, Part B, October 2015, pp. 652-663 (2015)

11. L. Braghirolli, J. L. Ribeiro, A. Weise, M. Pizzolato, Benefits of educational games as an introductory activity in industrial engineering education, Computers in Human Behavior, No. 58, pp. 315-324 (2016) 
12. Yu. Dimitrienko, E. Gubareva, New technology of mathematical training of engineering personnel, based on a neural network model of knowledge, Innovation in education, № 11, pp. 129-140 (2017)

13. Yu. Dimitrienko, E. Gubareva, K. Zubarev, S. Kudryavtseva, Methodological support of the continuing education of teachers on the development of online courses at bmstu, Science diary, № 11 (2018)

14. Yu. Dimitrienko, E. Gubareva, Hierarchical neural network model for mathematical knowledge and software NOMOTEX for mathematical training of engineers, IOP Journal of Physics: Conference Series, volume 1141012010 doi:10.1088/17426596/1141/1/012010 (2018)

15. Yu. Dimitrienko, E. Gubareva, T. Oblakova, Methodology for assessing knowledge on the course "Mathematical Analysis" in the digital environment NOMOTEX, Innovative development, № 9, pp. 8-11 (2018)

16. M. Janelli, E-Learning in Theory, Practice, and Research, No. 4, pp. 81-98 (2018)

17. I. Horváth, Innovative engineering education in the cooperative VR environment, 7th IEEE International Conference on Cognitive Infocommunications (CogInfoCom), pp. 359-364 (2016)

18. C.Y. Chao, Y.T. Chen, K.Y. Chuang, Exploring students' learning attitude and achievement in flipped learning supported computer aided design curriculum: A study in high school engineering education, Computer Applications in Engineering Education, 23(4), pp. 514-526 (2015)

19. J. Gutierrez, C.E. Mora, B. Anorbe-Diaz, A. Gonzalez-Marrero, Virtual Technologies Trends in Education, Eurasia Journal of Mathematics, Science and Technology Education, 13(2), pp. 469-486 (2017)

20. A.P. Markopoulos, A. Fragkou, P.D. Kasidiaris \& J.P. Davim, Gamification in engineering education and professional training, International Journal of Mechanical Engineering Education, 43 (2), pp. 118-131 (2015)

21. S. Junk, R. Matt, Workshop Rapid Prototyping - a new approach to introduce Digital Manufacturing, engineering education Proceedings of 14th International Conference on Information Technology Based Higher Education and Training, ITHET, IEEE Xplore, Lisbon, Portugal, pp. 1-6 (2015) 